\title{
Translation Study of British and American Literatures Based on Difference between Chinese and Western Cultures
}

\author{
Hanyue Zhang \\ College of Foreign Languages and Literature, Wuhan Donghu University, Wuhan Hubei, \\ 430212, China
}

\begin{abstract}
Keywords: Difference between Chinese and western cultures, British and American literature, Works translation.
\end{abstract}

\begin{abstract}
In the current society, social and cultural diversification degree is gradually enhanced and the influence of difference between Chinese and western cultures to the translation of British and American literatures becomes more remarkable. Thus in order to further promote the overall translational level of British and American literatures, it needs to optimize and adjust the translation strategies and gradually promote communication of Chinese and Western cultures in the translation field to drive better development of translation work. Based on the difference between Chinese and western cultures, this thesis systematically analyzes the translation strategies of British and American literatures, hoping to offer corresponding support and reference to the translation work of British and American literatures.
\end{abstract}

\section{Introduction}

Literature is an important component element of the national culture and the common treasure created during the social construction and development process. Different cultural forms of different nations reflect national basic thought, aesthetic tastes based on different historical development background, etc. and all diversified cultural forms together constitute the colorful world culture. As for the translation, it establishes corresponding bridge for the communication and exchange of each national culture in the world to some extent. And the literary translation is the best way for thought exchange and mind communication for each nation in the mental domain. Analyzing the British and American literatures could help us to rationally perceive British and American cultural connotations. Those excellent translations could enrich our artistic treasure house, promote better communication of Chinese and Western cultures and further carry forward the cultural output, not only developing our excellent cultures but also promoting prosperity of world literatures. Therefore, it is of some practical significance to explore the translation of British and American literatures based on the difference between Chinese and western cultures.

\section{Significance of Constructing Translation Thoughts Based on the Difference between Chinese and Western Cultures}

Language is the important carrier for a person to express thoughts. Different linguistic forms would reflect differences among different thinking models in essence. This shows that though apparently literary translation is the transformation of many linguistic forms, it is the exploration to different national modes of thinking in essence, which is to say, translation of British and American literatures is not only the transformation between language and words but also the join and communication of different national thoughts between the East and the West realized by translation of literatures. From the translation aspect of British and American literatures, establishing some translation thoughts 
based on the difference between Chinese and western cultures could help translators to promote their translation competence ${ }^{[1]}$. At the same time, since the classical British and American literatures are excellent works repeatedly deliberated and studied by litterateurs, those works are with not only rather advanced sentence patterns but also profound cultural connotations and lively language expressions, usually using a lot of idioms and languages with some insinuations at that time. The language expressive force is very strong. Thus during the translation process, translators should not only confirm the language of literary creation but also explore the deep thoughts that author wants to express by combining originator's thinking model and works' creation background and based on the difference between Chinese and western cultures, and further express it with lively and vivid languages. Only by this could guarantee the translation quality of British and American literatures, achieve "faithfulness, expressiveness and elegance" during translation process and promote translators' translational level. On this basis, after preliminarily establishing translation thoughts, translators should further polish the words and phrases, enhance translated works' artistry and cultural value and thus realize favorable communication of British and American literatures and literary thoughts. This shows that it is of great significance for translation competence promotion and the overall translation work development to establish some translation thoughts based on the difference between Chinese and western cultures, which should be paid high attention to.

\section{Analysis of the Difference between Chinese and Western Cultures}

\section{Difference in Values}

In the western culture, the basic value focuses on people, considering people as the core of social construction. And people should give play their functions to social construction and development. In China, the basic value attaches importance to group value, hoping to motivate and advance social development by group power. Specifically, Chinese culture attaches importance to collective interests, hoping individuals obeying to group, while western culture pays more attention to individualism, even some cultures focusing on sacrificing others' interest to satisfy individual interest. Such difference in values is reflected in language expression to some extent, for example, there is "self" series word group emphasizing self center in English while there is such folk adage as ten chopsticks holding group in Chinese, which show the difference in values between China and the West.

\section{Difference in National Customs}

Each national custom has its own personalized features. In Chinese society, from the ancient times, red was regarded as auspicious and joyous symbol, and even the symbol of power. In addition, such thought is obviously reflected in daily life, for example, "celebrity" refers to those with powers and known by the public; "booming" refers to the thriving days. However, in the western cultural system, red has different meaning, for example, "see red" means very angry while "go in red" the financial crisis. Thus, there is big difference in national customs between Chinese and Western culture ${ }^{\text {[2] }}$.

\section{Specific Difference in Thought and Consciousness}

Since there are big differences of the cultural background and social environment between Chinese and western cultures, people with traditional Chinese and western cultures would have big difference in modes of thinking. The westerners attach importance to linguistic constitution during language expression process, stressing a distinction between the important and the lesser one as well as the standard of sentence structure ${ }^{[3]}$. However, under the influence of Chinese culture, the language construction in our tradition thoughts would pay more attention to the harmonious beauty and would always regard verbs as the center of the whole sentence pattern during sentence-making process. Thus the created sentences have the progressive feature, with obvious Chinese characteristic. 


\section{Translation Strategy of British and American Literatures Based on Difference between Chinese and Western Cultures}

\section{Translation Theoretical Basis of British and American Literatures Based on Difference between Chinese and Western Cultures}

For a long time, the translation study in our country has some development and started to draw close to cultural comparison. Generally speaking, there are two aspects that need attention to promote translation work toward cultural development, domesticating translation that with target-language culture as the final destination and the foreignizing translation that with source language culture as the final destination. In the translation field, there is some correspondence between domesticating translation and foreignizing translation, which was firstly come up by Venuti, a famous American expert in the end of last century. And this theoretical summary was influenced by the relevant translation thoughts of Schleiermache, the German classical linguistic research expert who thought translation of literatures should insist two basic ways, little or many disturbance to the original author, translating on the basis of fully analyzing the original author's thoughts. Mona Baker, the famous research expert, once pointed out that translators should make judgment whether translated works with domestication or foreignization, analyze the cultural forms and reconstitution. Only if influence factor to change target culture value-relation is fully explored can its ultimate essence be confirmed ${ }^{[4]}$.

In the end of the 1980s, the Chinese scholar Liu Yingkai firstly analyzed the domestication or foreignization of translation and wrote Domestication - The Forked Road of Translation, officially starting the study to domestication or foreignization of translation in China. On this basis, Ge Xiaoqin also put forward that during that period to handle the domestication in literary translation, there were two preconditions for translators to use domestication, the domestication of loyally elaborating the original author's thoughts and the domestication of disloyalty to the original author's thoughts. There were some regular features to the domestication of loyally elaborating the original author's thoughts, belonging to the research category of source language being the center, while the latter could show obvious descriptiveness and the value orientation to the culture of target language to some extent. The domestication or foreignization can even be regarded as the deep extension of translation method of literal translation and free translation in the theoretical level. However, it was not the same with specific translation method of literal translation and free translation. It needs more attention in such aspects as cultural identity, discourse right and literariness of target language and source language of domestication and foreignization during translation process.

However, during the translation of British and American literatures, the domestication and foreignization can not be easily put into totally opposite sides, but to combine their own features of cultural thoughts and carry out corresponding domestication and foreignization. It should be recognized that absolute domestication and foreignization are not existed in objective translation world. Since domestication and foreignization in literary translation field could reflect obvious correspondence in both synchronic and diachronic aspects, no matter which translation strategy is chosen during the translation process would reflect corresponding mutual coverage to some extent ${ }^{[5]}$. It follows that the two important development directions, domestication and foreignization, should be paid attention in the translation of British and American literatures based on the difference between Chinese and western cultures. On this basis, translators should explore more specific translation methods to promote the translation literariness and artistry and ultimately realize different purposes of translation by rationally applying domestication and foreignization, providing diversified literary translation services for readers.

\section{Specific Translation Methods of British and American Literatures Based on the Difference between Chinese and Western Cultures}

There are several scientific translation methods to British and American literatures based on the difference between Chinese and western cultures. The choice of specific translation methods should 
refer to patterns of linguistic manifestation and modes of construction of different literatures. This thesis would specifically analyze applications of different translation methods.

Firstly, literal translation. It is to translate the British and American literatures based on the difference between Chinese and western cultures. The literal translation refers to reserve ideological contents in the original text and guarantee the translation could clearly reflect the original textual image and relevant cultural connotations with the limitation of no misunderstanding and using standard, for example, the literal translation of Pandora's box is "潘多拉魔盒" because of its typical historical allusion.

Secondly, free translation. During the translation of relevant British and American literatures, it would be influenced by the difference of Chinese and Western cultures. Thus in order to guarantee the translation literariness and artistry, sometimes it would choose to not reserve the images in original text, but to express the textual connotations by other linguistic paraphrasing, for example, the literal translation of Pulled their socks up should be "挂起他们的袜子", which can not express the original literary thoughts. Thus it should be "鼓起勇气" by combining the context, which could help readers to grasp the article thoughts and get their agreement more easily.

Thirdly, annotated literal translation. During the translation of British and American literatures based on the difference between Chinese and western cultures, it can also choose annotated literal translation. On the basis without original fundamental form, annotated literal translation could enhance the translation representation. For example, using annotated literal translation to "He that had no cross deserves no crown." can not only keep the original ideological connotations but also enhance its literariness with Chinese traditional culture "Hardship increases status." promoting the translation quality.

At last, annotated free translation. During the translation process, relevant translators would effectively delivery and exchange culture to keep the original cultural connotations. By analyzing the national features, they would use annotated free translation to national culture and promote the translation quality. Thus during the translation of British and American literatures, it can also use annotated free translation. For example, "When the old man on the frontier lost his mare, who could have guessed it was a blessing in disguise?" can be translated into "Misfortune might be a blessing in disguise." with annotation "Aloss, no bad thing".

\section{Summary}

From the aspect of literary translation, the translation process of literatures based on the difference between Chinese and western cultures is the process of exchanging and fusing Chinese and Western cultures in essence. Thus in order to promote translation quality, translators should grasp rational translation strategy on the basis of fully analyzing translation theory, guarantee the translation of British and American literatures with certain literariness and artistry on the basis of reflecting the works connotations, promote the cultural value and the overall translation quality in our country.

\section{References}

[1] Yan Wenzhen, Brief Analysis of Translation of British and American Literatures Based on Difference between Chinese and Western Cultures, Academic Journal of Zhejiang Business Technology Institute, 2014, 13(4):36-39.

[2] Zeng Yizhen, Several Enlightenments in Translation of British and American Literatures, Academic Journal of Chongqing College of Electronic Engineering, 2012, 21(4):64-66.

[3] Chang Lanhua, Zhang Ke, Translation Strategy of British and American Literatures under the Background of Cultural Differences, Mangzhong, 2016(2):77-78.

[4] Li Jia, Study on English Literary Translation, Business, 2013(27):320-320. 
[5] Ma Xiaohua, Ji Changhua, Cultural Difference and Countermeasures during the Translation from Chinese to English of Literatures, The Age, 2011(19):112. 